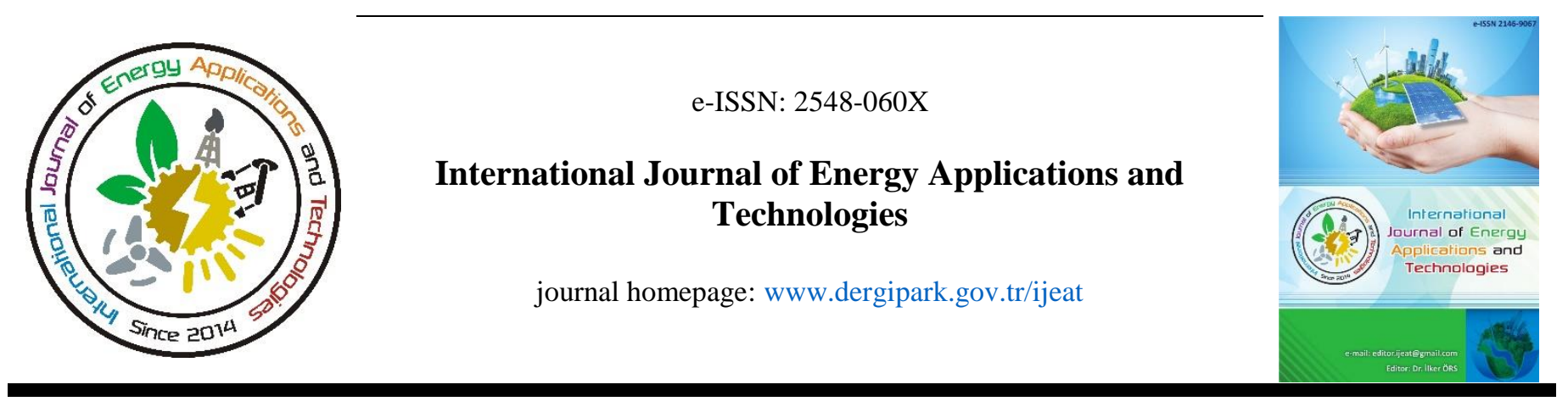

Review Article

\title{
Policy intervention and its consequences on the environment to combat climate change- A case from Bhutan
}

hosted by Jurkish

\author{
Hemlal Bhattarai \\ Centre for Lighting and Energy Efficiency Studies, Jigme Namgyel Engineering College, Royal University of Bhutan
}

\author{
ARTICLE INFO \\ * Corresponding author \\ b.hemlal@gmail.com \\ Received May 24, 2021 \\ Accepted November 10, 2021 \\ Published by Editorial Board \\ Members of IJEAT \\ (C) This article is distributed by \\ Turk Journal Park System under \\ the CC 4.0 terms and conditions.
}

doi: $10.31593 /$ ijeat.941741

\begin{abstract}
The world today is racing in the phase of the industrialization revolution where the concern is raised in many forums about the carbon footprint due to manmade actions giving thoughtprovoking highlight of actions towards energy usages and consequences to the environment. Strong linkage exists between energy and environments having direct relevance to the country's GDP. Countries are considering policies and strategies towards reducing Greenhouse Gas (GHG) emissions. Carbon dioxide $\left(\mathrm{CO}_{2}\right)$ is prime $\mathrm{GHG}$ that are released due to human activities. The developing countries are facing stiff challenges to balance their economic development and their dependency on the usage of energies. The study aimed to find out the cases of Bhutan with a target to understand the key actions that the country has been taking especially through policy interventions. The method used in this paper is a qualitative approach through collections of secondary data through literature review and drawing the results through the evidence in the forms of figures and tables. Results reveals that Bhutan has adopted multiple policies interventions, strategies and timely actions for environment and climate changes in fulfilling the 'Paris Agreement on Climate Change'. Bhutan has been instrumental in the implementations of relevant policies/regulations which is guided by the philosophy of Gross National Happiness (GNH) which follows the middle path of holistic socioeconomic development for economic growth as well in-line with Sustainable Development Goals (SDGs). Bhutan proudly stands as being the carbon-negative country where its annual consumption of $\mathrm{CO}_{2}$ is much more compared to what it produced.
\end{abstract}

Keywords: Bhutan; Greenhouse gas (GHG); Gross national happiness (GNH); Holistic socioeconomic development; Sustainable development goals (SDGs)

\section{Introduction}

Climate change and its mitigating actions are becoming an urgent call of time when there are noticeable impacts of climate changes faced across the globe. One of the promising contributors of climate change is the 'Green House Gas (GHG) Emissions' from the manufacturing, production, process and consumer sectors. The need for a standardized method for the inventory of GHG emissions is vital and the one developed by the GHG Protocol Initiative of the World Resources Institute and the World Business Council for Sustainable Development has proven to be crucial [1-2]. The global trend of GHG is becoming a concern in recent decades with the pace of globalization and industrialization. Even there is significant concern that needs to be addressed while concerning GHG in the growing economy of countries within Asia. Studies reflect that the three great countries in East Asia, namely Japan, the Republic of Korea and the People's Republic of China together share $28 \%$ of global GHG emissions approximately in 2014 [3]. The GHG emissions are mismatched across the globe where there are classifications of most GHG emissions emitting countries which though in countable number but has a significant contribution. Also, it has been found out that the majority of 
these countries whose GHG emissions are higher are least vulnerable to negative impacts of future climate change [4]. There is a need for countries to come together to address the issues pertaining to GHG and its implication on climate change. This calls for the countries to have stronger and effective climate change policies so that check and balance can be achieved the actions targeted to combat climate change. One of the crucial approaches for climate change mitigation is to critically focus on the reduction of GHG emissions. One such study reflected the optimal choice of policy instruments and found out that it is optimal to levy tax on both $\mathrm{CO}_{2}$ and methane which is the main contributor of GHG [5]. There has been considerable research done in terms of relating GHG emissions and climate change to quantify the impacts. The emissions traced to major industrial carbon producers and their potential climate responsibilities drawn models to quantify the contributions of historical and recent emissions traced [6]. The Paris Agreement (Paris Climate Agreement) has become instrumental in driving many countries across the globe in framing and prioritizing policies pertaining to $\mathrm{GHG}$ emissions (esp. $\mathrm{CO}_{2}$ ).

There are cases where the critical analysis of GHG emissions and economic growth nexus has been limitedly available for sub-Saharan Africa which is most venerable to climate change [7]. The climate risk is quite significant in the case of Asia where the studies highlighted that South and South East Asia are also reflected among the world's most vulnerable regions. Renewable energy resources for meeting power demand and also the role of decarbonized electricity generation is thus promising in the region [8-9]. Moreover, the countries in Asia and also any Least Developed Countries (LDC), Developing Countries has its stronghold in agriculture and studies shows that emissions of GHG from agriculture alone accounted for 10-12\% global GHG emission [10]. In terms of industries, the cement industry is also marked as one of the significant contributors to $\mathrm{CO}_{2}$ emissions and the needs of policies [11]. The role of countries in Asia becomes crucial in terms of having a conducive policy that can prove instrumental in climate change mitigation actions.

The Kingdom of Bhutan is a small and landlocked country that is sandwiched between China and India, located in South-East Asia with a population of 0.735 million with GDP per Capita is US\$ 2,879.07 and has a GDP growth rate of $7.99 \%$ [12]. The country based on the Himalayas range is seeing the growing impacts of climate change. Bhutan has $38,395 \mathrm{~km}^{2}$ of the land of which $70 \%$ of it is covered with forest [13]. The country-based philosophy of Gross National Happiness (GNH) as its guiding measure for the economic development policy. GNH is based on four effective pillars of which two pillars are 'Sustainable and Equitable Socioeconomic Development' and 'Conservation of Environment' which are guiding principles to balance the socio-economic development with that of the environment [14]. Indeed, GNH is a combination of philosophy and form of governance for RGoB that uses to guide national policymaking that has a stronghold of Bhutanese tradition and religious belief [15].

The Constitution of Bhutan in its Article 5 under Section 3 also focuses on environment conservation and mandates that in all times to come, the country should have at least $60 \%$ of the total land under forest cover [16]. This has put the focus of various relevant sectors to come up with policies, strategies and mandates that will supplement GNH and the Constitution of Bhutan.

The policies and constitution of Bhutan are also favorable factors to focus more on extraction and use of hydro-power potential for meeting domestic energy requirements and also export to India which by 2025 can offset up to 22.4 Million Tons of CO2 per year [17]. The Kingdom of Bhutan today proudly stands as an environmental leader and net-carbonnegative country primarily due to its vast landmasses (about $70 \%$ in the current situation) covered with forest.

\section{Materials and Methods}

This research is a qualitative approach that is based on the literature survey banked on the secondary data that has been collected through the research paper, policy and regulation document and relevant stakeholders' official website. The findings from the relevant literature are analyzed in form of tables and figures where necessary and the results are drawn from the findings.

\subsection{Policies and mandates}

Policies play a crucial role in planning and executing actions. Today when GHG emission, climate change and sustainability are in forefront of thought and actions. The term sustainability has become a universal appeal in the current time where urgency in our efforts toward a healthy planet should be of focus [18].

The small landlocked country Bhutan's socio-economic development is based on a multidimensional (holistic) development strategy known as GNH since1970s and it is considered important indices than GDP when comes to measuring its progress. The philosophy happens to be a blessing and medium of recognition for Bhutan in its recent decades and has certainly exposed Bhutan to wider audiences. The overview of GNH models along with its governing four pillars and domains are as shown in the figures below.

There is a stronghold on the preservation of the environment and sustainable \& equitable socio-economic development which focuses on the development driven with the implementation of these policies. The four pillars are further supported with 9 domains where one of the domains is on the 
environment [14]. Development is a priority of any economy including that of Bhutan where environmental impacts will be significant. Bhutan is strongly committed to environmental conservation with its guiding philosophy of development and its constitution mandate, but in the meantime need for economic development was felt. Accordingly, Bhutan committed to follow the 'The Middle Path' of development leading to sustainable development. The typical model pertaining to Bhutan from earlier studies is shown in the figure below.

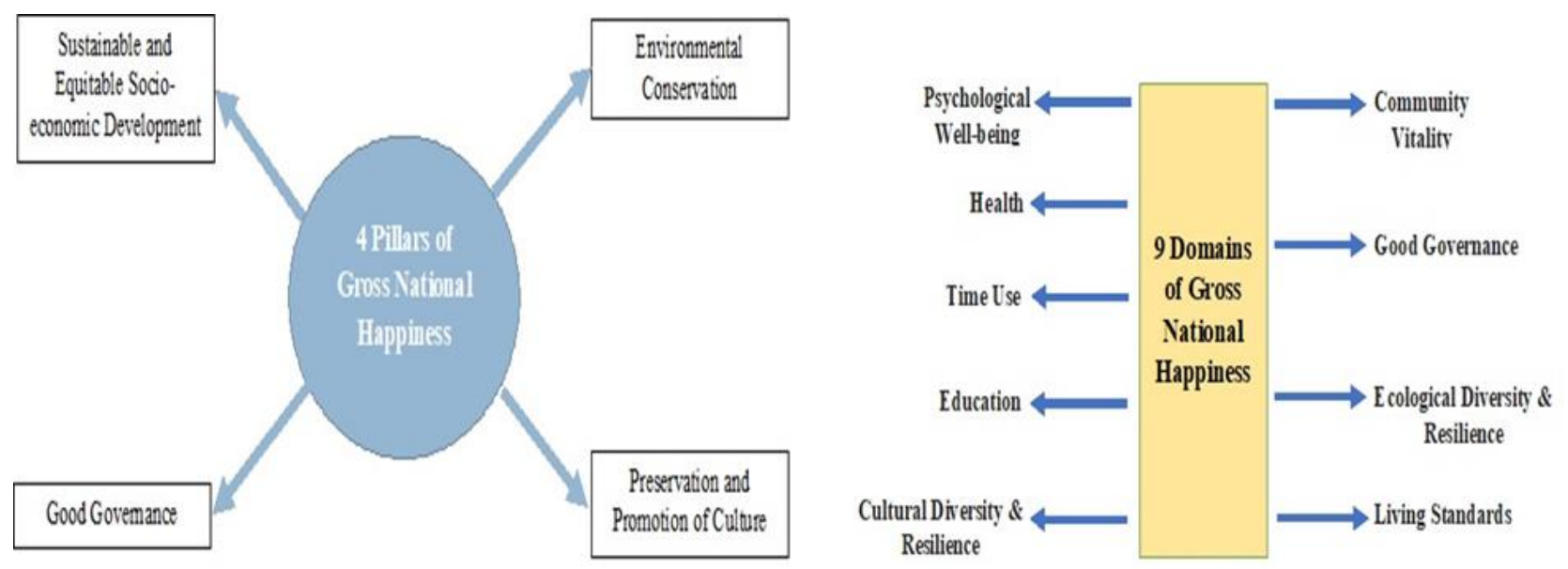

Fig. 1. The 4 Pillars (a) and 9 Domains(b) of GNH

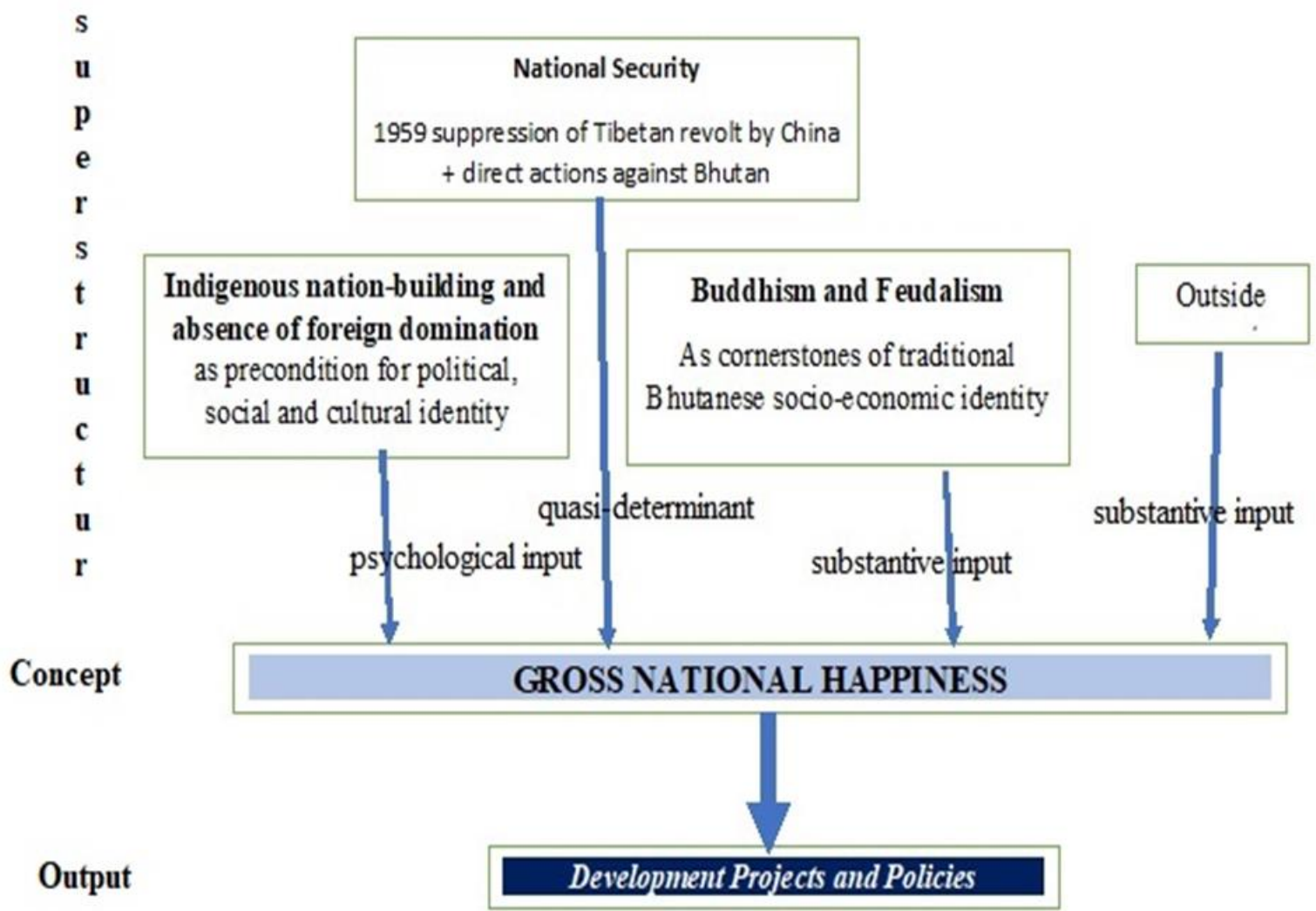

Fig. 2. Bhutan model of development [19]

The middle path of development is a focus on holistic socioeconomic development whereby happiness and society are considered above all aspects of development. Whatever socio-economic development needs to take place; it makes no sense if there is missing societal happiness. The GNH philosophy is one such device that focuses its approaches towards these dimensions and prioritizes GNH methodologies in addressing the issues of check and balance in terms of development and societal happiness. The integration of GNH and its societal happiness models which address the issues of needs, holistic development, responsible use of resources, equitability and sustainable society, and happiness skills are as reflected in the figure below. 


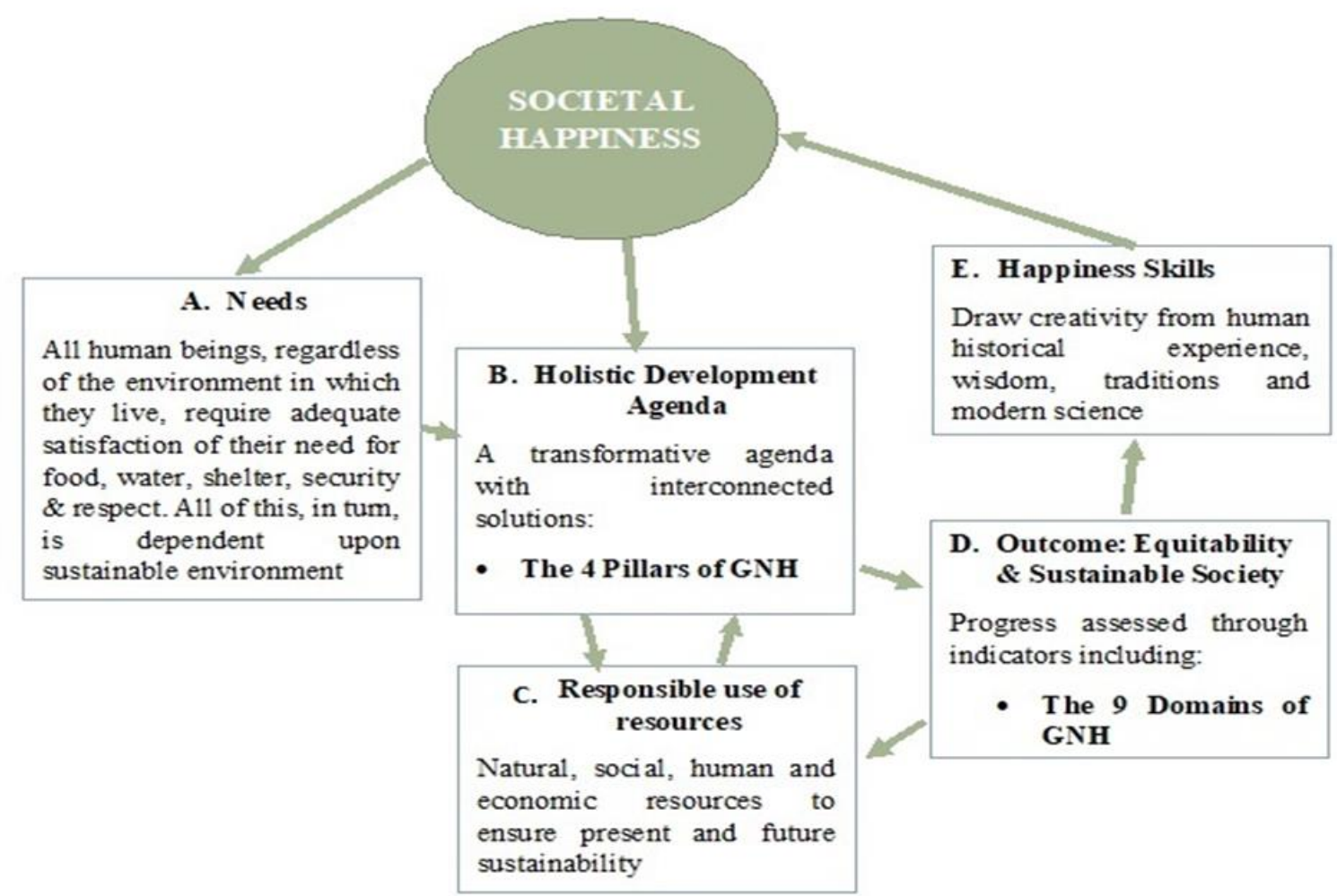

Fig. 3. A good model to explain Gross National Happiness [20]

Bhutan put focuses on GNH models as a result GNH assessments must be used towards evidence-based decisionmaking for the achievement of GNH (13th RTM GNHC $\mathrm{RGoB}, 2017)$. This is crucial to balance the socio-economic

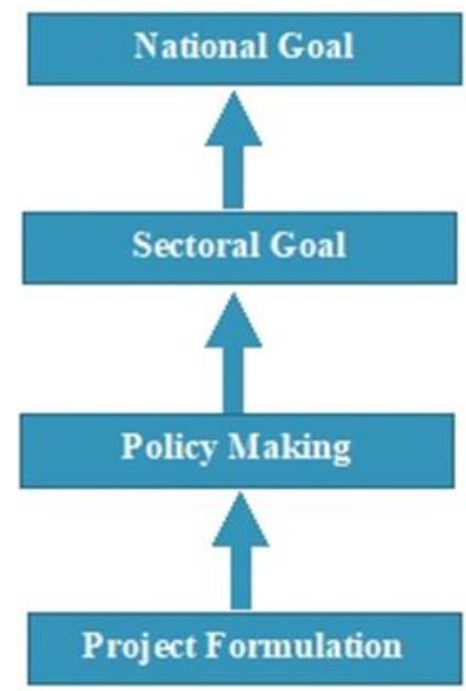

developmental activities in a guided manner and with strong policies intervention. The following figure reflects the framework for integrating GNH into policies.

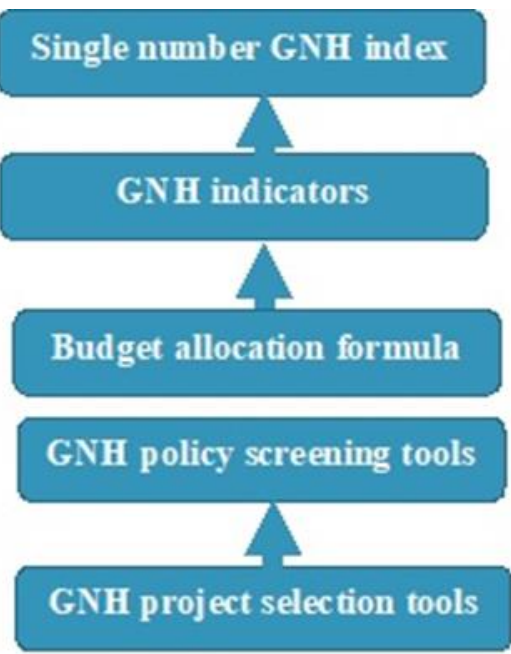

Fig. 4. Integrating GNH into policies [21]

This is the baseline for Bhutan to focus on its GHG emissions and remain committed to its goal of being a carbon-neutral country. The GHG emissions of Bhutan recorded in 1994 were: $\mathrm{CO}_{2}=228.46 \mathrm{Gg}, \mathrm{CH} 4=19.22 \mathrm{Gg}, \mathrm{N}_{2} \mathrm{O}=2.13 \mathrm{Gg}$, $\mathrm{NOx}=0.71 \mathrm{Gg}$ and $\mathrm{CO}=2.29 \mathrm{Gg}$ which is insignificant by global standards. This finding felt that GHG emissions in the future will require continued study and monitoring so that we are always reminded of our actions. It was at COP 15, 2009 where Bhutan has released a statement titled the 'Declaration of the Kingdom of Bhutan-The Land of Gross National 
Happiness to Save our Planet' in which the country pledged to protect the environment 'keep absorbing more carbon than it emit-and to maintain the country's status as a net sink for GHG' [22] and reaffirmed to remain so in 2015 in COP 21. The report also highlighted that between the first GHG Inventory year of 1994 and the second inventory year of 2000, emissions from energy grew at 21.4 percent a year mostly due to transport and industry growth. Emissions from industrial processes grew at about 8.7 percent a year.

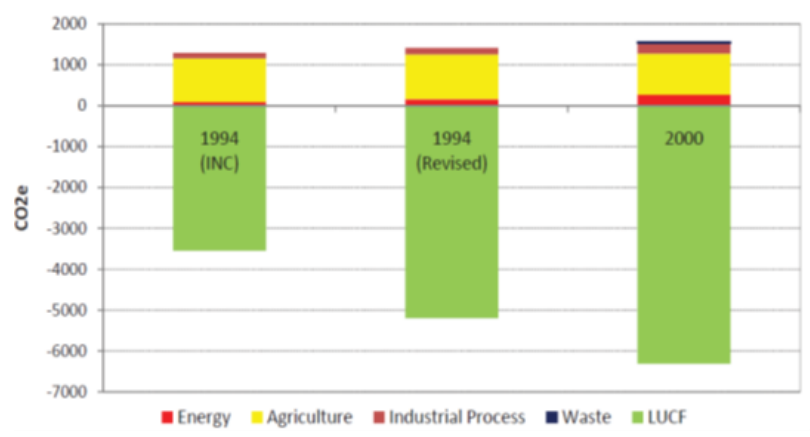

Fig. 5. Total GHG emissions trend of Bhutan [22]

\section{Global $\mathrm{CO} 2$ emissions continue to rise Emissions in gigatonnes of carbon dioxide}
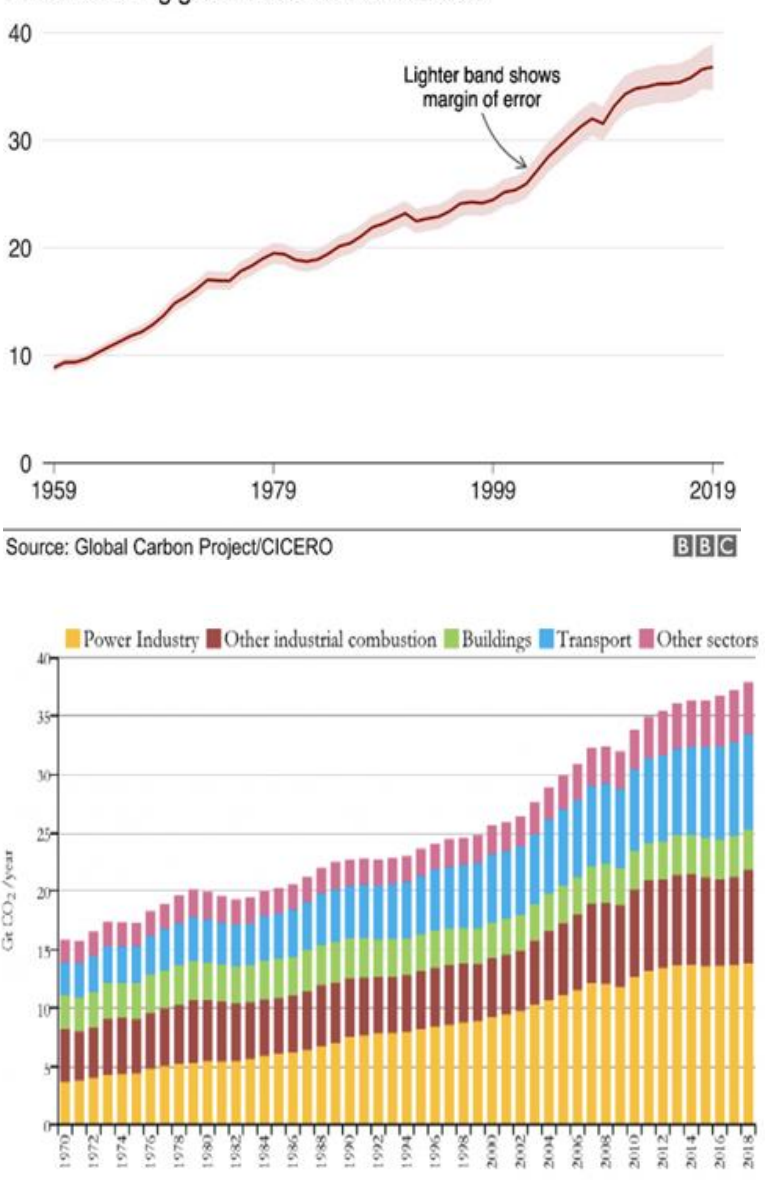

Fig. 6. Global $\mathrm{CO}_{2}$ emissions trend and distribution [23]
Fossil fuel consumption is the major contributor to carbon dioxide emissions globally as well in Bhutan. The figures below show the global $\mathrm{CO}_{2}$ emissions trend which is rising rapidly in the $21^{\text {st }}$ century and also the sectors wise $\mathrm{CO}_{2}$ emissions trends where $\mathrm{CO}_{2}$ emissions from the power industry increasing by 82 percent since 1990 . Further, the same report highlights that in 2018, global $\mathrm{CO}_{2}$ emissions from fossil fuel combustion and processing rose to 1.9 percent as compared to the previous year.

A report from the National Environment Commission of Bhutan highlighted the net GHG emission of $-5572.50 \mathrm{Gg}$ $\mathrm{CO}_{2} \mathrm{e}$ in 2015 which shows a decrease of 23.11 percent from that of 1994 levels and an increase of 3.55 percent from that of 2000 levels [24]. The GHG emissions and sequestration of Bhutan are as shown below.

A record below shows the trend of fossil fuel carbon dioxide emissions for the last 6-7 years is noticed to be growing up to 16 percent (maximum) in some years since 2010 .

Bhutan being a small developing country with numerous challenges based on its geographical terrains, population, economy and social situations has declared its intention and commitments to become and remain carbon-neutral in perpetuity.

As part of the Paris Agreement on Climate Change, Bhutan's Nationally Determined Contribution (NDC) shared its commitment to remain carbon-neutral for all the times to come. With the estimated 2.2 million tons of $\mathrm{CO}_{2}$ emitted, gross carbon sequestration by forests will not be exceeded, making Bhutan actions to the forest a prime role-player. To complement and supplement, Bhutan Constitution requires the country to keep at least $60 \%$ of its total land area under forest cover at all times.

Bhutan forest cover about $70 \%$ of the country's total land area, sequestration an estimated 6.3 million tons of carbon dioxide $\left(\mathrm{tCO}_{2} \mathrm{e}\right)$ which is a greater boon to the country. The National Environment Commission (NEC), Royal Government of Bhutan (RGoB) has submitted to the 2nd National Communication to UNFCCC in 2000, that total GHG emissions excluding land-use change and forestry are 1.56 million $\mathrm{tCO}_{2} \mathrm{e}$ (LUCF). LUCF produced nearly 6.3 million $\mathrm{tCO}_{2} \mathrm{e}$ GHG drain. As a result, Bhutan's forestry sector is critical in the achievement of its NDC goals [26].

The constitution of Bhutan is a boon for strategic plans and implementations of GNH policies in Bhutan. As such three acts primarily focused on the environment are i) Forest Act, ii) Waste Act and iii) Water Act [27].

Some of the policies, guidelines and mandates which directly address the country's priorities as mitigation plans and actions that are intended to support low carbon development pathways are listed below. 


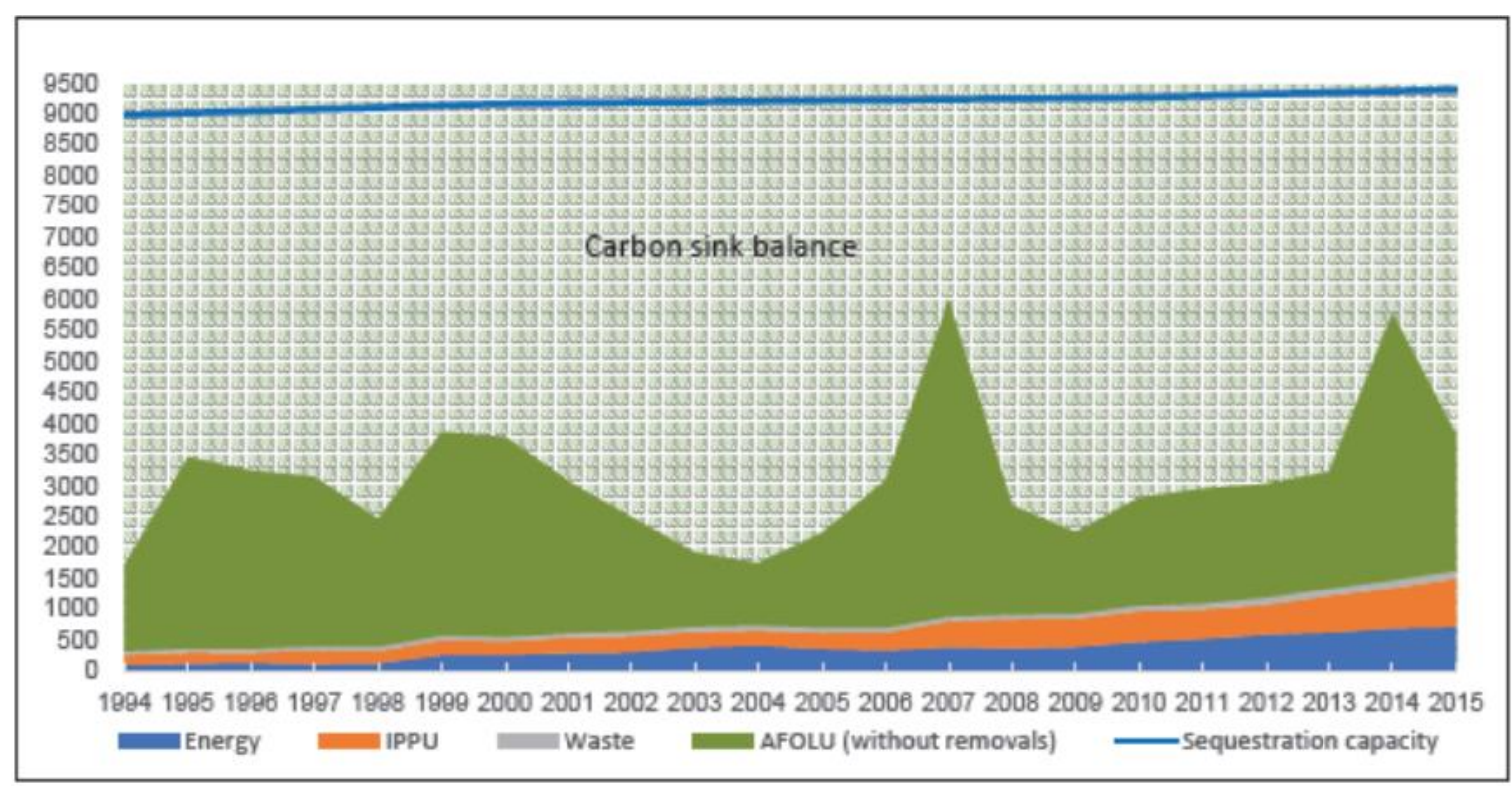

Fig. 7. GHG Emission and Sequestration (1994-2015) [24]

Table 1. Bhutan Fossil Carbon Dioxide $\left(\mathrm{CO}_{2}\right)$ emissions (2010-2016) [25]

\begin{tabular}{|c|c|c|c|c|c|c|}
\hline Year & $\begin{array}{c}\text { Fossil } \mathrm{CO}_{2} \\
\text { Emissions (tons) }\end{array}$ & $\begin{array}{c}\mathrm{CO}_{2} \text { emissions } \\
\text { change }\end{array}$ & $\begin{array}{c}\mathrm{CO}_{2} \text { emissions } \\
\text { per capita }\end{array}$ & Population & Pop. change & $\begin{array}{c}\text { Share of World's } \\
\mathrm{CO}_{2} \text { emissions }\end{array}$ \\
\hline 2016 & $1,682,100$ & 6.14 percent & 2.28 & 736,708 & 1.21 percent & 0.00 percent \\
\hline 2015 & $1,584,853$ & 2.87 percent & 2.18 & 727,876 & 1.23 percent & 0.00 percent \\
\hline 2014 & $1,540,583$ & 5.53 percent & 2.14 & 719,055 & 1.24 percent & 0.00 percent \\
\hline 2013 & $1,459,914$ & 6.94 percent & 2.06 & 710,237 & 1.23 percent & 0.00 percent \\
\hline 2012 & $1,365,161$ & 0.54 percent & 1.95 & 701,581 & 1.19 percent & 0.00 percent \\
\hline 2011 & $1,357,834$ & 16.43 percent & 1.96 & 693,298 & 1.14 percent & 0.00 percent \\
\hline 2010 & $1,166,188$ & 9.23 percent & 1.70 & 685,503 & 1.06 percent & 0.00 percent \\
\hline
\end{tabular}

\subsection{Environmental assessment Act 2000}

This Act establishes procedures for the assessment of the potential effect of strategic plans, policies, programs and projects on the environment, and for determining strategies and interventions to mitigate possible negative consequences while promoting environmental benefits.

\subsection{National environment protection Act 2007}

An Act to provide for the establishment of an effective system to conserve and protect the environment through the National Environment Commission or its successors

\subsection{National Forest Policy 2011}

Bhutan is a net GHG sequester largely due to its vast forest cover. The National Forest Policy is geared towards sustainable management of forests including the maintenance of the health and vitality of forests and a minimum of $60 \%$ forest cover (as enshrined in the Constitution).

\subsection{National strategy and action plan for low carbon} development (carbon-neutral strategy), 2012

Bhutan National Strategy and Action Plan for Low Carbon Development was developed to help the country meet its goal of remaining carbon-neutral.

\subsection{Economic Development Policy (2017)}

It is developed with a vision to have a sustainable and selfsufficient economy supported by a knowledge-based society governed by the philosophy of GNH (Gross National Happiness).

Each of these Acts is instrumental in the conservation of the environment and also the implementation of sustainable \& equitable socio-economic development.

Since 1961, Bhutan adopted a planned and guided five-year economic development plan (FYP) which is regulated by the Gross National Happiness Commission (GNHC) of the RGoB. Bhutan's declaration to remain Carbon-neutral, 60\% forest cover at all times \& Environmental Protection, 
Economic Development Policy emphasizes on "green growth" are crucial interventions which are worth noticing. The 11th Five Year Plan (2013-2018) of Bhutan has prioritized its focus 'To achieve Carbon-neutral \& Climate Resilient Development' making its policy intervention much concrete for action towards carbon emissions and climate change.

It is also clear that Bhutan's economic development policy [28] and other supporting regulations provide incentives towards meeting the carbon-neutral commitment through fiscal and tax measures for increasing energy efficiencies and pollution control in industries, transport and other sectors.

The incorporation of Sustainable Development Goals (SDGs) has been mainstreamed into Bhutan's $12^{\text {th }}$ Five Year Plan (July 2018-June 2023) with priority in three goals (i.e. Goal 1, Goal 13 and Goal 15) as Bhutan continue to commit in its actions to materialize SDGs. Similarly, the 11th Five Year Plan (2013-2018) has identified 'climate-resilient and carbon-neutral development' of the focuses of Bhutan. The country has also achieved almost $99 \%$ of people with access to electricity, Bhutan Sustainable Hydropower Development policy 2008, Energy Efficiency \& Conservation Policy (EE\&C) in place, and Domestic Feed-in Tariff under formulation, Provision of 100 units of electricity per month for free to rural households are some of the recent strategies followed [29].

Energy systems and system change are complex methods that need to be critically reviewed while moving in energy usage switching which requires complex system modeling [30]. RGoB emphasizes that EE\&C measures shall be promoted for sustainable use of energy across all sections of the consumers through the adoption of a National Energy Efficiency and Conservation Policy by 2017. Bhutan's strategy also emphasizes a green and self-sufficient economy by 2020 , promoting optimal use of the country's ecological and natural resources as well as the pursuit of energyefficient productive methods [28].

The major energy-consuming sectors in the Country include building, appliances, transport and industry. Energy consumption in each of these sectors in 2014 was as follows: Building and appliance sector: 270,356 TOE,

Industry sector: 241,972 TOE

Transport sector: 121,218 TOE.

To address these growing concerns, the National Energy Efficiency Roadmap was drawn up accordingly [31].

Furthermore, one such guideline establishes the impact of energy efficiency on the country's GHG emissions in line with the country's targets with about 0.59 million $\mathrm{tCO}_{2} \mathrm{e}$ emissions reduction potential from the implementation of EE\&C measures [31]. The report also highlighted that from 0.27 million $\mathrm{tCO}_{2} \mathrm{e}$ in 2000 to 0.79 million $\mathrm{tCO}_{2} \mathrm{e}$ in 2013 , emissions from the energy sector rose by $191.6 \%$. Emission from manufacturing processes rose by $154.3 \%$ from 0.24 million $\mathrm{tCO}_{2} \mathrm{e}$ to 0.6 million $\mathrm{tCO}_{2} \mathrm{e}$ over the same period. Though emissions from the energy sector are small $(12.5 \%$ of GHG sequestration potential), the growth rate has been noticed is significant. The report highlighted the intervention measures for energy efficiency (EE) in building, appliances, industries and cross-cutting sectors for its implementations. Accordingly, detailed EE interventions and targets were set against each sector. The main objective of this guide is to enable and guide RGoB to integrate the EE\&C activities into the $12^{\text {th }}$ FYP and the subsequent five-year plans with the objective of efficient energy consumption, and reduced GHG emissions thereby leading to lower energy intensity and maintaining the carbon-neutral commitment.

Bhutan also has seen a significant increase in the transport sector which accounts for greater shares in the country's total GHG emissions. So, focuses were given on efficient fuels usage and energy-efficient transportation systems making the policies and support mechanism favorable to promote a green transport system in Bhutan [32].

Bhutan will be able to meet its commitment to remain carbon-neutral as per its strategy with an action plan developed for low carbon. Bhutan with $0.15 \mathrm{~kg} \mathrm{CO}_{2} \mathrm{e} / \mathrm{USD}$ of GDP power purchase-parity, is a low carbon intensity as compared to $0.46 \mathrm{~kg} \mathrm{CO}_{2} \mathrm{e} / \mathrm{USD}$ for the developing countries. The low strength, on the other hand, is due to Bhutan's high rate of carbon-neutral hydropower in Bhutan [24]. The report also highlighted that the emissions from agriculture are a major source of pollution, accounting for half of all emissions, while a quarter each of it is from energy and industry. Bhutan's high share of emissions from agriculture relative to other countries represents the country's high rate of carbon-neutral hydropower generation compared to many other countries' high reliance on fossil fuels for power generation.

With the projections made referring to the official population and GDP forecasts of Bhutan, according to the results, emissions will be 4.7 million $\mathrm{tCO}_{2} \mathrm{e}$ in 2040 , which is more than double the amount in 2010, but still less than the projected sequestration of 6.3 million $\mathrm{tCO}_{2} \mathrm{e}$.

It further stressed that with the focused effort to improve energy efficiency in all sectors and increase the share of renewable energy about $10 \%$ and $42 \%$ reduction respectively in 2040 from the baseline can be achieved. This indicates the potential for policy intervention in the area of energy efficiency and the shares of renewable energy as viable approaches for Bhutan.

Bhutan has a huge hydropower capacity, and with the construction of new dams, exploitation of this resource is increasingly increasing. Currently, the hydropower installed capacity is $1615 \mathrm{MW}$ and about $70 \%$ of the energy generated is being exported to India [33]. Based on the reference the 
total hydropower generation in 2009 was $6,925 \mathrm{GWh}$ (installed broad hydro capacity 1,480 MW) with $78 \%$ of that going to India. Bhutan's NDC indicates the possibility of offsetting 22.4 million $\mathrm{tCO}_{2} \mathrm{e}$ through the export of hydroelectricity by 2025 . In the Indian electricity system, marginal output emits $1.0 \mathrm{tCO}_{2} \mathrm{e} / \mathrm{MWh}$ of carbon dioxide. To put it another way, the energy exported to India in 2009 svoided 5.4 million $\mathrm{tCO}_{2}$ e carbon emissions. Bhutanese hydropower generation thus benefits both Bhutan and the regional carbon balance.

Under current situations, decarbonization of energy systems is no longer a theoretical matter. There are many examples of successful cases that can be explored as a reference. All these cases provide solid evidence of the existence of effective solutions for a transition to a low-carbon society. The Gross National Happiness concept is Bhutan's overall governing direction and was in place domestically before the SDGs. Its position within the context of energy transition needs to be analyzed to learn lessons to apply to the SDGs [34].

Furthermore, it is good to refer the Kigali Amendment to the Montreal Protocol, which is an international agreement whose objective is to gradually phase down the consumption and production of hydrofluorocarbons (HFCs), which is a policy move intended to avoid up to $0.50 \mathrm{C}$ of global warming by the end of the century, while continuing to protect the ozone layer. The amendment (the 5th Amendment to Montreal Protocol) which was in force since January 2019 commits countries to reduce the production and consumption of Hydrofluorocarbons (HFCs) which are used as alternatives to Ozone-depleting substances (ODs) by $80 \%$ by the mid2040s.

The report from the National Media of Bhutan [35] reflects that from 2015 to 2018 , about 11,216 metric tons of $\mathrm{CO}_{2} \mathrm{e}$ were emitted from HFCs consumed in cooling and heating technologies. It also highlights that currently; Bhutan is in its final stage of phasing out hydrochlorofluorocarbons (HCFCs) with $67.5 \%$ reduced so far and expects to remove $97.5 \%$ by 2025 while keeping $2.5 \%$ for the servicing use. Furthermore, Bhutan has ratified the Kigali Amendment in 2019 and has committed to reducing the consumption of HFCs starting 2024 with a target reduction of $80 \%$ by 2045 .

\subsection{Challenges}

Bhutan has been experiencing a rise in vehicle numbers in recent times. This has resulted in an increase in vehicular tariff due to the economic development of the country and also an increase in the import of fossil fuel in the transport sector from 2002 to 2014 by almost 8 folds and projected to rise [31]. Needs to address as well as curtail the rapid growth of fossil fuel consumption and carbon emissions in the transportation sectors was felt by RGoB. Bhutan made its initiative in 2014 as one of the steeping measures. Since then, the promotion of low emissions vehicles as a preferred mode of urban transportation remains key to addressing growing problems associated with traffic growth and carbon emissions.

It is noted that the industrial and transport sectors are responsible for the highest emissions growth in the country with 0.24 million $\mathrm{tCO}_{2} \mathrm{e}$ in 2000 to 0.6 million tons in 2013. The growth is contributed due to growth in vehicles and industries in the last decades. Bhutan's carbon emissions in 2014 were 2.4 million $\mathrm{tCO}_{2} \mathrm{e}$ emissions [36] and this number is far below the sink capacity of 6.3 million tons.

Bhutan has come up with the country's Transport Vision 2040 which critically emphasizes using more energyefficient transport modes, enhancing transportation options, using renewable fuels and technologies, implementing information technology, and providing incentives for fuelefficient and green vehicles as a regulation strategy. Accordingly, the vision constitutes an integrated approach to three modes of transportation, namely: road, urban and civil aviation [37].

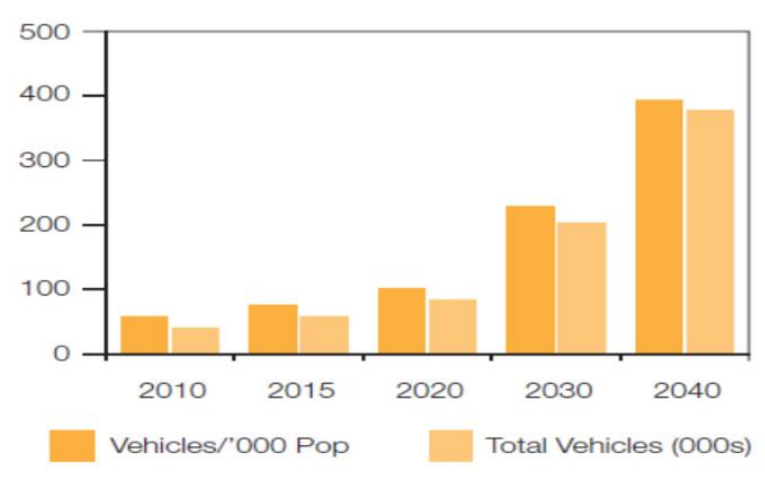

Fig. 8. Growth in Vehicle Ownership [37]

Furthermore, the study baseline projection in the table below shows that emissions will be 4.7 million $\mathrm{tCO}_{2} \mathrm{e}$ in 2040 which is more than two times of which it in 2010. Still in 2040 also the emissions are below the expected sequestration of 6.3 million $\mathrm{tCO}_{2} \mathrm{e}$ according to the baseline report. During the period 2010-2040, energy-related emissions will increase by nearly $90 \%$, while non-energy-related emissions will increase by nearly $110 \%$. According to the study, the most significant rise is expected in industrial processes, with emissions increasing to four-time in 2040 as compared to what in 2010.

Bhutan's 2010 economic development policy places a strong emphasis on green growth as a means of fostering industrial and private sector development. Despite that, there are growing carbon emissions due to the economic development of the country. 
Table 2. Baseline projection of carbon emissions [37]

\begin{tabular}{|c|c|c|c|c|c|}
\hline & 2005 & 2010 & 2020 & 2030 & 2040 \\
\hline Energy Related Mission (kt $\left.\mathrm{CO}_{2} \mathrm{e}\right)$ & 357 & 468 & 905 & 906 & 885 \\
\hline Energy intensive industries & 62 & 69 & 221 & 189 & 159 \\
\hline Other industries & 70 & 91 & 154 & 180 & 208 \\
\hline Domestic aviation & - & - & 2 & 2 & 2 \\
\hline Road transport & 177 & 228 & 376 & 361 & 348 \\
\hline Tertiary sector & 18 & 35 & 56 & 60 & 60 \\
\hline Residential Sector & 28 & 42 & 91 & 106 & 98 \\
\hline Agricultural and forestry & 2 & 3 & 5 & 8 & 11 \\
\hline Non-energy related emissions $\left(\mathrm{kt} \mathrm{CO}_{2} \mathrm{e}\right)$ & 1.454 & 1.764 & 3.492 & 3.678 & 3.837 \\
\hline Industrial processes & 243 & 465 & 1.947 & 1.947 & 1.947 \\
\hline Livestock & 567 & 567 & 567 & 567 & 567 \\
\hline Crop & 550 & 603 & 734 & 811 & 903 \\
\hline Urban municipal solid waste & 94 & 130 & 246 & 353 & 422 \\
\hline Total (kt CO2e) & 1.811 & 2.232 & 4.398 & 4.585 & 4.723 \\
\hline Population & 634.982 & 695.822 & 809.397 & 886.523 & 964.838 \\
\hline Tons CO2e per capita & 2,9 & 3,2 & 5,4 & 5,2 & 4,9 \\
\hline
\end{tabular}

Furthermore, the country is bracing with the impacts of climate change where the need for heating and cooling seems increasing at a faster rate. This demand for implementation for amenities to meet the growing requirement. As a result, consumption of HFCs will be on the higher side and it requires greater efforts in terms of policies intervention and actions.

\section{Results and Discussion}

Bhutan has been proactive with a series of policies and intervention measures that have been developed and implemented keeping in mind the mandate of the constitution of the country and its holistic developmental approaches (GNH) that support Bhutan to achieve its milestone to be carbon negative. The numerous policies, regulations and supports mechanism has been instrumental in the prospects of land use, forest development and protection, energy extractions and usage enhance in promotions of renewable and clean energy technologies including cleaner transport systems are the most visible approaches in the case of Bhutan.

The study also highlighted that there is a growing concern in the field of transportation as well as industrialization. This is one of the major challenges the country has to address in maintaining its race of holistic and balanced socio-economic development. Bhutan has enforced policies related to economic development, forest management and conservation, energy efficiency \& conservations, energy efficiency policy, energy efficiency roadmap, transportation vision 2040 which has prioritized environment preservation and conservation with focuses on sustainable socio-economic development. The various policies and interventions along with initiatives from RGoB are very dynamic based on its own learning and implementations which is visible from a small country Bhutan and such examples can prove handy for many countries through learning from experiences in its actions for climate change.

\section{Conclusion}

It is evident that Bhutan is a carbon-neutral country and has pronounced it as carbon negative country. Bhutan's policies interventions, commitments and actions are the strongest tools in mainstreaming the action against GHG emissions. As global climate change is a clear indicator of environmental impacts that is prominent, there is a growing threat to livelihoods. Bhutan as a tiny country is one of those exceptional cases where due diligence is followed in meeting the pace of its socio-economic development keeping the focuses on its environment. This case can be instrumental for developing and developed economies to explore and access the carbon footprint of their own. The cases can be one of the intervention measures that can be explored and where possible incorporated so that our action towards climate change and GHG emissions are timely \& appropriate in the pace of socio-economic development and economic growth. The development and $\mathrm{CO}^{2}$ and other greenhouse gases have a strong linkage which can be handled with conducive policies in place so the vulnerable low-income and middleincome countries should not be a victim of climate change and its consequences. Simultaneously policies, regulations and acts should control the actions of developed countries which have greater threads to environments and climate change due to its large scales socioeconomic actions for economic growth. 


\section{$\underline{\text { ORCID }}$}

H. Bhattarai

0000-0002-6512-1685

\section{References}

[1] Pawelzik, P., Carus, M., Hotchkiss, J. et.al. 2013. Critical aspects in the life cycle assessment (LCA) of bio-based materials - Reviewing methodologies and deriving recommendations. Resources, Conservation and Recycling, 73, 211-228.

[2] GHGP. Product life accounting and reporting standard. The Greenhouse Gas Protocol World Resources Institute \& World Business Council for Sustainable Development; 2011. http://www.ghgprotocol.org/ standards/product-standard

[3] Stavins, R. N., and Stowe, R. C. 2018. International cooperation in East Asia to address climate change. Harvard Project on Climate Agreements With the support of The Harvard Global Institute. https://www.belfercenter.org/sites/default/files/files/pu blication/harvard-project-east-asia.pdf. (February 2018.)

[4] Althor, G., Watson, J. E., and Fuller, R. A. 2016. Global mismatch between greenhouse gas emissions and the burden of climate change. Scientific Reports, 6(1). 1-6.

[5] Zhang, X., and Xu, J. 2018. Optimal policies for climate change: A joint consideration of $\mathrm{CO}_{2}$ and methane. Applied Energy, 211, 1021-1029.

[6] Ekwurzel, B., Boneham, J., Dalton, M. W. et.al. 2017. The rise in global atmospheric $\mathrm{CO}_{2}$, surface temperature, and sea level from emissions traced to major carbon producers. Climatic Change, 144(4), 579590.

[7] Adzawla, W., Sawaneh, M., and Yusuf, A. M. 2019. Greenhouse gasses emission and economic growth nexus of sub-Saharan Africa. Scientific African, 3, $\mathrm{e} 00065$.

[8] Climate Analytics, Decarbonising South and South East Asia: Shifting energy supply in South Asia and South East Asia to non-fossil fuel-based energy systems in line with the Paris Agreement long-term temperature goal and achievement of Sustainable Development Goals. 1-80. (May 2019.)

[9] NEC, RGoB, 2020. Third National Communication to the UNFCCC, National Environment Commission of Bhutan,

https://unfccc.int/sites/default/files/resource/TNC\%20 of\%20Bhutan\%202020.pdf. 1-182. (November 2020.)

[10] MacLeod, M., Moran, D. et.al. 2010. Developing greenhouse gas marginal abatement cost curves for agricultural emissions from crops and soils in the UK. Agricultural Systems, 103(4), 198-209.

[11] Rehan, R. and Nehdi, M. 2005. Carbon dioxide emissions and climate change: Policy implications for the cement industry. Environmental Science \& Policy, $8(2), 105-114$.

[12] NSB, RGoB. Population and Housing Census of Bhutan. National Statistics Bureau, Bhutan, 2017.

[13] NSB, RGoB. Statistical Year Book. National Statistics Bureau, Bhutan, 2019.

[14] GNH Centre, Bhutan, What is GNH. http://www.gnhcentrebhutan.org/what-is-gnh/the-4pillars-of-gnh/ (20th April 2021.)

[15] Montes, J., and Bhattarai, S. R. 2018. Buddhist biopower? - Variegated governmentality in Bhutan's gross national happiness agenda. Geoforum, 96, 207216.

[16] RGoB, The Constitution of the Kingdom of Bhutan, Royal Government of Bhutan, Bhutan, 2008.

[17] Wester, P. Mishra, A. Mukherji, A. and Shrestha, A. B. The Hindu Kush Himalaya assessment: Mountains, climate change, sustainability and people. Springer, 2019.

[18] Tobias, M. C. and Morrison, J. G. Why life matters: Fifty ecosystems of the heart and mind, Springer, 2014

[19] Stefan, P. Gross National Happiness-Bhutan's Vision of Development and its challenges.

[20] Tho, H. V. Gross National Happiness as an alternative development paradigm and its relevance for community living, Euroasia learning Institute for happiness and wellbeing, 2018,

https://elihw.org/wpcontent/uploads/2018/11/ELI_Camphill_and_TTG_V2 _WEB-ilovepdf-compressed.pdf

[21] GHNC, RGoB. 13th Round Table Meeting, Gross National Happiness for the global goals, Gross National Happiness Commission, 2017, https://www.gnhc.gov.bt/13rtm/

[22] NEC, RGoB, Second National Communication to UNFCCC, National Environment Commission of Bhutan, 2011 , https://unfccc.int/resource/docs/natc/snc_bhutan.pdf.

[23] Crippa, M. Oreggioni, G. Guizzardi, D. et.al. Fossil CO $\mathrm{CO}_{2}$ and GHG emissions of all world countries, EUR 29849 EN, Publications Office of the European Union, Luxembourg, 2019, ISBN 978-92-76-11100-9.

[24] NEC, RGoB, Third National Communication to UNFCCC, National Environment Commission of Bhutan, 2020, http://www.nec.gov.bt/wpcontent/uploads/2020/10/TNC_2020_Oct_Final.pdf. 
[25] Worldometers, Bhutan Co2 emission, 2021, https://www.worldometers.info/co2-emissions/bhutanco2-emissions/. (20 April 2021.)

[26] Jamyag D. Dorji, S. et al. 2013. Public Awareness of Environmental Policies in Bhutan, BJRD, 1-14.

[27] MoEA, RGoB, Economic Development Policy, Ministry of Economic Affairs, 2016.

[28] RGoB, Sustainable Development and Happiness, 2018, https://sustainabledevelopment.un.org/content/docume nts/19369Bhutan_NSDGR_Bhutan_2018.pdf.

[29] Bale, C. S. Varga, L. and Foxon, T. J. 2015. Energy and complexity: New ways forward, Applied Energy, 138, 150-159.

[30] DRE, RGoB, National Energy Efficiency Roadmap, Department of Renewable Energy, 2019.

[31] Bhattarai. H. 2021. Policy Driven Initiative for Promoting Electric Vehicles to Combat Climate Change in the Developing Countries: A case from Bhutan, IOER-IMRJ, Vol. 3, No. 1, pp. 11-20.

[32] Druk Green Power Corporation Ltd., 2021, https://www.drukgreen.bt/

[33] Månberger, A. 2018. Deep Decarbonization and Energy Security for Low-Carbon Societies, Green Growth and Decarbonization of Energy Systems in a Changing World. Rocamora, A. R. \& Ishikawa, T. (eds.). Hayama: Institute for Global Environmental Strategies (IGES), p. 14-16.

[34] National Newspaper, Bhutan Green House Gas Emission to Rise if nothing changes, Kuensel Coorporation, Bhutan, https://kuenselonline.com/bhutans-greenhouse-gasemissions-to-rise-if-nothing-changes/, 2021.

[35] Yangka, D. and Newman, P. 2018. Bhutan: Can the 1.5 ${ }^{\circ} \mathrm{C}$ agenda be integrated with growth in wealth and happiness? Urban Planning, 3(2), 94-112.

[36] ADB, Bhutan Transport 2040 Integrated Strategic Vision, Asian Development Bank, 2013. 